\title{
Therapeutic effects of Schisandra chinensis on the hyperprolactinemia in rat
}

\author{
SO-HYE HONG ${ }^{1}$, MEI LI ${ }^{2}$, EUI-BAE JEUNG ${ }^{3}$, GEUN-SHIK LEE ${ }^{4}$, \\ EUI-JU HONG ${ }^{5}$, YOUNG-WHAN $\mathrm{CHOI}^{2}$ and BEUM-SOO AN ${ }^{1}$
}

\begin{abstract}
${ }^{1}$ Department of Biomaterials Science, College of Natural Resources and Life Science, Pusan National University, Miryang-si, Gyeongsangnam-do; ${ }^{2}$ Department of Horticultural Bioscience, College of Natural Resources and Life Science, Pusan National University, Miryang-si, Gyeongsangnam-do; ${ }^{3}$ Laboratory of Veterinary Biochemistry and Molecular Biology, College of Veterinary Medicine, Chungbuk National University, Cheongju, Chungbuk; ${ }^{4}$ College of Veterinary Medicine and Institute of Veterinary Science, Kangwon National University, Chuncheon, Gangwon 200-701;

${ }^{5}$ Laboratory of Biochemistry and Molecular Biology, College of Veterinary Medicine, Chungnam National University, Daejeon, Gangwon, Republic of Korea
\end{abstract}

Received December 15, 2016; Accepted February 6, 2017

DOI: $10.3892 /$ ijo.2017.3881

\begin{abstract}
Prolactin (PRL) is secreted from the pituitary gland in response to eating, mating, and ovulation. Increased serum concentration of PRL during pregnancy contributes to enlargement of the mammary glands of the breasts and prepares for production of milk. However, high PRL levels derived from prolactinoma and hyperprolactinemia induce physiological disorders such as infertility and early menopause. Natural compounds isolated from $S$. chinensis have been known to possess anti-oxidative, anti-inflammatory and anti-diabetic effects. In the present study, we examined the therapeutic effect of S. chinensis and its single compounds on hyperprolactinemia in the pituitary gland. In rat pituitary cells, PRL expression levels were examined using real-time PCR and western blot assay. Crude $S$. chinensis extract and its single compound, gomisin N, reduced mRNA and protein levels of PRL in GH3 cells. In addition, cell proliferation and PRL target gene expression in cells were modulated by $S$. chinensis. Similar to the in vitro experiments, crude $S$. chinensis extract and gomisin N reduced PRL levels in the pituitary and serum of immature female rats. These results show that $S$. chinensis and its single compound, gomisin
\end{abstract}

Correspondence to: Dr Beum-Soo An, Department of Biomaterials Science, College of Natural Resources and Life Science, Pusan National University, 50 Cheonghak-ri, Samrangjin-eup, Miryang-si, Gyeongsangnam-do 627-706, Republic of Korea

E-mail: anbs@pusan.ac.kr

Dr Young-Whan Choi, Department of Horticultural Bioscience, College of National Resources and Life Science, Pusan National University, Miryang-si, Gyeongsangnam-do 627-706, Republic of Korea

E-mail: ywchoi@pusan.ac.kr

Key words: Schisandra chinensis, gomisin N, prolactin, hyperprolactinemia, pituitary
$\mathrm{N}$, are regulators of PRL production and may be candidates for treatment of hyperprolactinemia and prolactinoma.

\section{Introduction}

The pituitary gland is a tiny organ found at the base of the brain (1). The pituitary gland is divided into three sections: anterior, intermediate and posterior lobes (2). The pituitary gland produces many hormones, including oxytocin, antidiuretic hormone, growth hormone, thyroid-stimulating hormone (TSH), luteinizing hormone ( $\mathrm{LH}$ ) and folliclestimulating hormone (FSH), that travel throughout the body and direct physiological processes $(1,3)$. The anterior lobe is mainly involved in the development of the body, the sexual maturation and the reproduction (4). Hormones produced by the anterior lobe regulate growth and stimulate the adrenal and thyroid glands as well as the ovaries and testes.

The pituitary also generates prolactin (PRL), which is a 23-kDa polypeptide hormone secreted by lactotroph cells of the anterior pituitary gland (4). Pituitary PRL secretion is regulated by endocrine neurons in the hypothalamus, which secrete dopamine to act on dopamine receptors located on lactotrophs for inhibition of PRL secretion (5). PRL acts in an endocrine, autocrine and paracrine manner through prolactin receptor (PRLR) and a large number of cytokine receptors (6). PRL plays an important role in the reproductive health of both women and men. Specifically, it stimulates mammary glands to produce milk (lactation); increased serum concentrations of PRL during pregnancy cause enlargement of mammary glands of the breasts and prepare for production of milk. PRL also controls secretion of sex steroid hormones (4). Highly elevated levels of PRL reduce levels of estrogen in women and testosterone in men. The effects of mildly elevated levels of PRL are much more variable, as estrogen levels in women may either substantial increase or decrease (7).

Since PRL performs multiple physiological functions, uncontrolled levels of PRL are associated with many diseases. 
Hyperprolactinemia, which is noted in most cases of gonadotroph pituitary adenoma, is defined as a high concentration of PRL (8). One common cause of hyperprolactinemia is tumor growth on the pituitary gland, known as prolactinoma. If PRL levels are high, a doctor will test thyroid function and asks about other conditions and medications known to increase PRL secretion. Diagnosis of prolactinoma by magnetic resonance imaging (MRI) is the most sensitive method for detecting pituitary tumors and determining their size (9).

Schisandra chinensis (Turcz.) Baill (S. chinensis) has a well-recognized history in traditional Chinese medicine. $S$. chinensis fruits contain a variety of pharmacologically active lignans such as gomisin A, B, C, D, E, F, G, K3, N and $\mathrm{J}$, together with schisandrol $\mathrm{B}$, schisandrin (SS) and schisandrin C (SC). These compounds have diverse pharmacological activities, including detoxificant, anti-oxidant, anti-carcinogenic, anti-hepatotoxic, anti-inflammatory and anticancer activities $(10,11)$. Two major lignans, SS and gomisin A (GA), have gained attention due to their therapeutic effects (11). For instance, SS possesses biological activities, including hepatoprotective, antiviral and neuroprotective effects $(12,13)$. However, the effects of $S$. chinensis on pituitary and hormonal regulation have not been addressed. In the present study, therefore, we examined the effects of $S$. chinensis and its single compounds on regulation of PRL and growth hormone production in the pituitary. In addition, the therapeutic potential of S. chinensis was evaluated by in vitro and in vivo experiments.

\section{Materials and methods}

Plant material extraction. Dried fruits of $S$. chinensis were ground to a fine powder and successively extracted at room temperature with $n$-hexane, EtOAc and $\mathrm{MeOH}$. Hexane extract was evaporated in vacuo and chromatographed on a silica gel column $(70 \times 8.0 \mathrm{~cm})$ with a step gradient of $0,5,10,20$ and $30 \%$ EtOAc in hexane (each 1 1). Fraction 11 was separated on a silica gel column $(100 \times 3.0 \mathrm{~cm})$ with $25 \%$ hexane in $\mathrm{CHCl}_{3}$ to give five subfractions. Fraction 11IA was further purified by column chromatography on silica gel eluted with $\mathrm{CHCl}_{3}$-acetone (19:1) to give gomisin $\mathrm{N}(\mathrm{GN})$. Fraction 8 was separated on a silica gel column $(100 \times 3.0 \mathrm{~cm})$ with $\mathrm{CH}_{2} \mathrm{Cl}_{2}$ to give SC. Fractions 36, 37 and 38 were separated on a silica gel column $(100 \times 3.0 \mathrm{~cm})$ with $5 \% \mathrm{CH}_{2} \mathrm{Cl}_{2}$ in acetone to give $\mathrm{SS}$.

For extraction of GA and $\alpha$-iso-cubebene (CU), dried fruits of $S$. chinensis were ground and extracted with $n$-hexane, $\mathrm{CHCl}_{3}$ and methanol. Hexane extract was evaporated in vacuo and chromatographed on a silica gel column $(100 \times 10 \mathrm{~cm})$ with a step gradient $(0,5$ and $20 \%)$ of ethyl acetate in hexane and $5 \%$ methanol in $\mathrm{CHCl}_{3}$ to obtain 38 fractions as described before. (22) Fraction 11 was separated on a silica gel column $(100 \times 3.0 \mathrm{~cm})$ with hexane-chloroform-methanol $(75: 25: 1$ by volume) to obtain four fractions. Fraction 3 was separated on a Sephadex column $(100 \times 3.0 \mathrm{~cm})$ with methanol (KH11ICIC). Finally, KH11ICIC was separated on a silica gel column $(115 \times 3.0 \mathrm{~cm})$ with $5 \%$ acetone in chloroform to yield GA. Fraction 11 was separated on a silica gel column $(100 \times 3.0 \mathrm{~cm})$ with $15 \%$ acetone in $\mathrm{CH}_{2} \mathrm{Cl}_{2}$ to obtain nine fractions. Next, fraction 2 was separated on a silica gel column $(100 \times 3.0 \mathrm{~cm})$ with $15 \%$ acetone in $\mathrm{CH}_{2} \mathrm{Cl}_{2}$ to yield $\alpha$-iso-cubebene $(\mathrm{CU})$. Pure CU was identified by HPLC on a Phenomenex Luna C18 column (Phenomenex, 150x4.6 mm ID; $5 \mu \mathrm{m}$ particle size) with an acetonitrile-water-reagent alcohol gradient at a flow rate of $1.0 \mathrm{ml} / \mathrm{min}$.

GH3 cell culture and treatments. GH3 rat pituitary epitheliallike tumor cells were seeded in culture medium and allowed to attach during $24 \mathrm{~h}$ of incubation, after which the seeding medium was removed and replaced with experimental medium added to $100 \mathrm{U} / \mathrm{ml}$ of penicillin and $100 \mu \mathrm{g} / \mathrm{ml}$ of streptomycin for $24 \mathrm{~h}$ before treatment. Chemicals were dissolved in $\mathrm{EtOH}$, diluted with experimental medium and added to the wells. Cells were treated with crude extract (crude, $0.1 \mathrm{mg} / \mathrm{ml}$ ) and single compounds, including GN, GA, SC, SS and CU $(20 \mu \mathrm{M})$ or EtOH as a vehicle control.

Experimental animals and treatments. Immature female Sprague-Dawley $(n=19)$ rats were acquired from Samtako Bio (Osan, Republic of Korea). Animals were housed at the Pusan National University Laboratory Animal Resources Center, which is accredited by the AAALAC and Korea FDA, according to the National Institutes of Health guidelines. the rats were housed in cages under a 12-h light/dark cycle and a constant temperature of $23 \pm 1^{\circ} \mathrm{C}$. The Ethics Committee of Pusan National University (Busan, Republic of Korea) approved all experimental animal procedures (approval no. PNU-2015-0921). Rats were treated daily with crude (200 mg/kg), GN (20 mg/kg), progesterone (P4, $1 \mathrm{mg} / \mathrm{kg})$ or corn oil (vehicle control) via oral (crude and GN) or subcutaneous injection (P4) from postnatal days 13-19. Dosage was adjusted according to changes in body weight (BW). All animals were sacrificed using $\mathrm{CO}_{2}$ gas for preparation of tissue and serum samples.

Quantitative real-time PCR ( $q$-PCR). Total RNA was extracted using TRIzol reagent (Invitrogen, Carlsbad, CA, USA) according to the manufacturer's protocol. Concentration of total RNA was measured by a spectrophotometer. DNA (cDNA) was prepared from total RNA $(1 \mu \mathrm{g})$ by reverse transcription (RT) using M-MLV reverse transcriptase (Invitrogen) and random primers (9-mers; Takara Bio, Shiga, Japan). q-PCR was performed using cDNA template $(2 \mu \mathrm{l})$ and SYBR-Green (6 $\mu$ l; Toyobo Co., Ltd., Shiga, Japan) with specific primers. Primer sequences used for PRL, PRLR, growth hormone and $\beta$-actin are as follows: PRL (left, 5'-AGT CTG TTC TGG TGG CGA CT-3' and right, 5'-GAA GTG GGG CAG TCA TTG AT-3'); PRLR (left, 5'-CCT CTG CAC TTG CTT TCG TC-3' and right, 5'-ATC GAT TCC TCC ATC TGT CC-3'); grow th hormone (left, 5'-CTG GCT GCT GAC ACC TAC AA-3' and right, 5'-AAG CGA AGC AAT TCC ATG TC-3'); $\beta$-actin (left, $5^{\prime}$-ACC AAC TGG GAC GAT ATG GAG AAG-3' and right, 5'-TAC GAC CAG AGG CAT ACA GGG ACA-3'). q-PCR was carried out for 40 cycles using the following parameters: denaturation at $95^{\circ} \mathrm{C}$ for $15 \mathrm{sec}$, annealing and extension at $70^{\circ} \mathrm{C}$ for $60 \mathrm{sec}$. Fluorescence intensity was measured at the end of each extension phase. The threshold value for the fluorescence intensity of all samples was set manually. The reaction cycle at which PCR products exceeded this fluorescence intensity threshold during exponential phase of PCR amplification was considered to be the cycle of threshold (CT). Expression of the target gene was quantified 

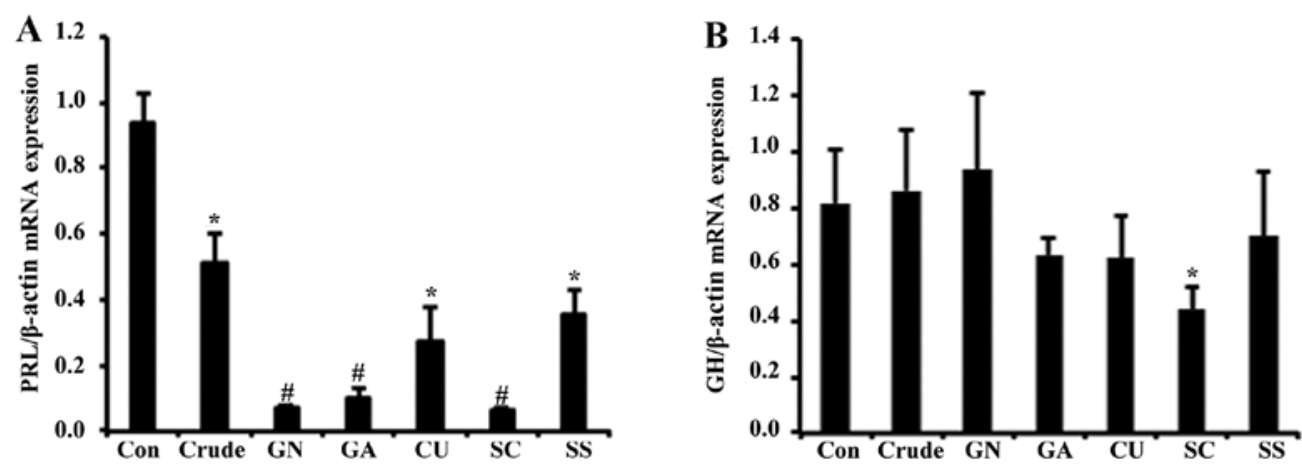

Figure 1. Regulation of PRL and growth hormone mRNA expression by S. chinensis and its single compounds in GH3 cells. Total mRNA was harvested from GH3 cells treated with crude extract and single compounds. Transcription levels of PRL (A) and growth hormone (B) were analyzed by q-PCR compared to the control group. Expression levels of PRL and growth hormone were normalized to that of $\beta$-actin. Data are expressed as the mean \pm SD. $P<0.05$ compared to the control group; ${ }^{*} \mathrm{P}<0.02$ compared to the control group.

relative to that of $\beta$-actin, a housekeeping gene, based on the comparison of CTs at constant fluorescence intensity.

Western blot analysis. Protein samples were extracted from GH3 cells with cell lysis buffer ( $20 \mathrm{mM}$ Tris, $100 \mathrm{mM} \mathrm{NaCl}$, $0.5 \% \mathrm{NP}-40,0.5 \mathrm{mM}$ EDTA and $0.5 \%$ protease inhibitor cocktail). A total of $25 \mu \mathrm{g}$ of protein was separated by $10-12 \%$ sodium dodecyl sulfate polyacrylamide gel electrophoresis (SDS-PAGE) and then transferred to nitrocellulose membranes (Dogen, Seoul, Korea). Membranes were subsequently blocked for $2 \mathrm{~h}$ with 5\% skim milk (Difco ${ }^{\mathrm{TM}}$ ) in tris-buffered saline (TBS) with $0.05 \%$ Tween-20 (TBS-T). After blocking, membranes were incubated with antibodies specific for PRL (diluted 1:500) overnight at $4^{\circ} \mathrm{C}$ as well as horseradish peroxidase (HRP)-conjugated anti-goat secondary antibodies in 5\% skim milk with TBS-T for $1 \mathrm{~h}$. Luminol reagent (Bio-Rad Laboratories) was used to visualize antibody binding. Each blot was scanned using Gel Doc 1000, version 1.5 (Bio-Rad Laboratories) and band intensities were normalized to $\beta$-actin levels.

Cell proliferation assay. GH3 cells $\left(3 \times 10^{4}\right.$ cells/well) were seeded on 96-well plates in $200 \mu \mathrm{l}$ of Dulbecco's modified Eagle's medium (DMEM) containing 10\% fetal bovine serum (FBS), $100 \mathrm{U} / \mathrm{ml}$ of penicillin and $100 \mu \mathrm{g} / \mathrm{ml}$ of streptomycin. After $24 \mathrm{~h}$ of incubation, the seeding medium was removed and replaced with experimental medium (phenol red-free DMEM supplemented with $10 \%$ charcoal-dextran-treated FBS, $100 \mathrm{U} /$ $\mathrm{ml}$ of penicillin and $100 \mu \mathrm{g} / \mathrm{ml}$ of streptomycin) for $24 \mathrm{~h}$ before treatment. Cells were treated with all single compounds $(20 \mu \mathrm{M}$ each) or EtOH as a vehicle control for $24 \mathrm{~h}$, after which $50 \mu \mathrm{l}$ of MTT solution $(2 \mathrm{mg} / \mathrm{ml})$ was added to each well in $200 \mu \mathrm{l}$ of medium without phenol red and the plates incubated for $4 \mathrm{~h}$ at $37^{\circ} \mathrm{C}$. Dimethyl sulfoxide (DMSO) was added to all wells and mixed thoroughly to dissolve the dark blue crystals. After a few minutes at room temperature to ensure that all crystals were dissolved, absorbance in the wells was measured at $570 \mathrm{~nm}$ with a reference wavelength of $650 \mathrm{~nm}$.

Statistical analyses. Results are presented as the mean \pm standard deviation (SD). Data were analyzed using SigmaPlot 10.0 (Systat Software, Inc., San Jose, CA, USA). P $<0.05$ were considered statistically significant.

\section{Results}

Regulation of PRL expression and secretion by S. chinensis and its compounds in $\mathrm{GH} 3$ cells. To investigate the effect of $S$. chinensis on pituitary PRL production, GH3 cells were treated with crude, GN, GA, CU, SC and SS for $24 \mathrm{~h}$. Transcription levels of PRL were reduced in response to crude by $\sim 2$-fold (Fig. 1A), and all single compounds of S. chinensis significantly reduced PRL mRNA levels. As GH3 cells are known to synthesize another critical substance, the growth hormone, we also analyzed the effect of S. chinensis on transcriptional regulation of the growth hormone. In contrast to PRL levels, mRNA expression of growth hormone was not significantly altered by crude or any single compounds, suggesting that the effect of $S$. chinensis is specific to the regulation of PRL (Fig. 1B).

Since the effects of GN, GA and SC were more dominant compared with those of CU and SS, we conducted further experiments using these three compounds. When the cells were treated with crude and single compounds (GN, GA and SC), protein levels of PRL were reduced $\sim 2$-fold by crude and GN (Fig. 2A). To test secretion of PRL, cell culture media was collected and subjected to western blot assay. In the results, PRL secretion was also reduced by all treatment groups, which is consistent with the mRNA and protein results (Fig. 2B). In all experiments, GN showed the most significant alteration of PRL production among single compounds.

Dose- and time-dependent regulation of PRL synthesis. Regulation of PRL by GN, a single compound of S. chinensis, was further explored in a dose- and time-dependent manner. Pituitary cells were treated with various concentrations $(5,10$, 20 and $50 \mu \mathrm{M}$ ) of $\mathrm{GN}$ for $24 \mathrm{~h}$, resulting in significant reduction of PRL protein levels and secretion at concentrations of 10 to $50 \mu \mathrm{M}$ in a dose-dependent manner (Fig. 3A). Basal PRL expression levels were reduced according to culture time, suggesting that PRL synthesis may be controlled by autocrine regulation of PRL itself. When cells were treated with GN, PRL protein expression was downregulated from 16 to $24 \mathrm{~h}$ compared with the negative control during the same time. GN treatment also reduced secretion of PRL in culture media of GH3 cells from 16 to $24 \mathrm{~h}$, which is similar to mRNA and protein expression levels (Fig. 3B). 

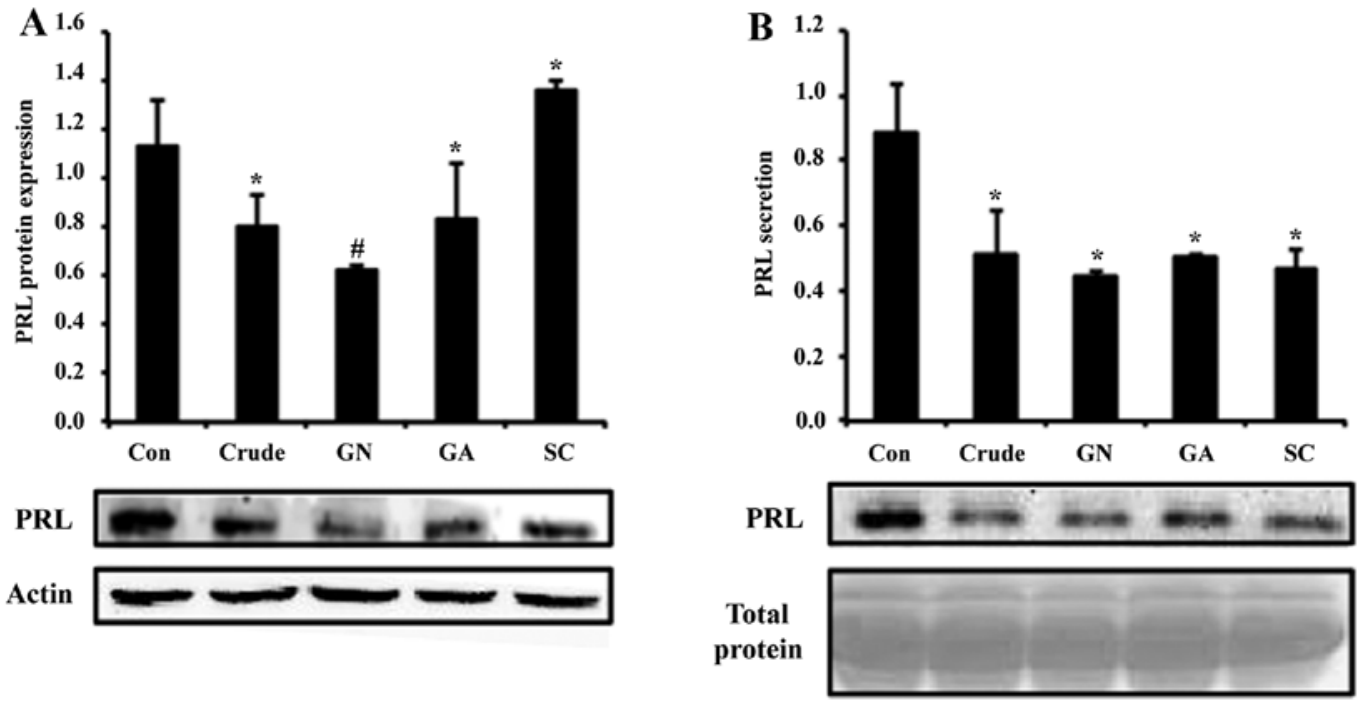

Figure 2. Regulation of PRL protein expression and production by S. chinensis and single compounds in GH3 cells. Translation level of PRL (A) was analyzed by western blot assay. Protein production of PRL (B) in growth medium secreted from GH3 cells was analyzed. Data are expressed as the mean \pm SD Expression level of PRL was normalized to that of $\beta$-actin. Protein content in growth medium was normalized to total proteins stained with Coomassie brilliant blue. ${ }^{*} \mathrm{P}<0.05$ compared to the control group; ${ }^{\#} \mathrm{P}<0.02$ compared to the control group.
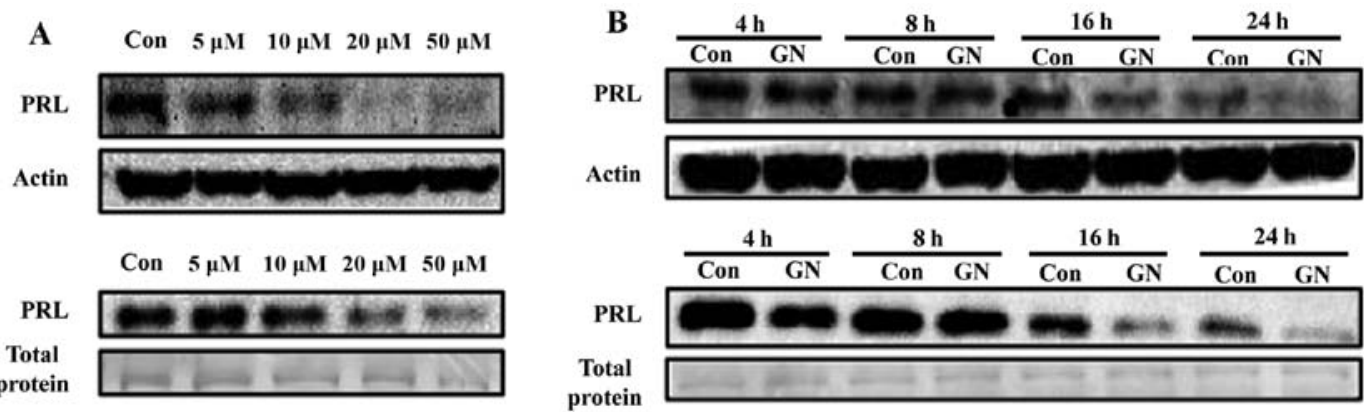

Figure 3. Dose- and time-dependent prolactin expression and production induced by GN. Protein expression of PRL after GN treatment was tested in a (A) dose- and (B) time-dependent manner. Data are expressed as the means \pm SD of triplicate experiments. Translation level of PRL was normalized to that of $\beta$-actin. Protein content in growth medium was normalized to total proteins stained with Coomassie brilliant blue.

Effect of S. chinensis and GN on GH3 cell proliferation and $P R L$ target gene. To evaluate whether or not GN regulates viability of GH3 cells, we performed MTT assay (Fig. 4A). GH3 cells were treated with crude and GN for $24 \mathrm{~h}$, after which the cell viability was measured. Cell proliferation was inhibited by $\sim 20 \%$ in both crude and GN groups compared to the control. These results showed that $S$. chinensis and its single compound, GN, inhibit not only PRL production but also viability of PRL-secreting cells. To examine the expression of PRL target gene after crude and GN treatment, mRNA levels of the PRL-specific receptor PRLR were tested. Both crude and GN enhanced expression of PRLR up to 4-fold compared to the control (Fig. 4B).

Regulation of $P R L$ and $P R L R$ production by S. chinensis and $G N$ in immature rats. Based on our in vitro findings, we next examined the effects of $S$. chinensis and GN in vivo using immature female rats. Rats were orally injected with crude, $\mathrm{GN}$, or corn oil as a vehicle control from postnatal days 16 to 18 and sacrificed on day 19. Rats were also treated with P4 by subcutaneous injection as a positive control for reduction of PRL. The ratio of organ weight to body weight indicated no significant alteration of liver and kidney weights in all animals, suggesting that there is no toxic effect by the treatment (Fig. 5A). Transcription level of PRL in the pituitary of immature female rats was examined using real-time PCR. Expression of PRL was reduced $\sim 3$-fold by crude and 2-fold by GN treatment (Fig. 5B). To test PRL secretion levels, serum of immature female rats was analyzed by western blot assay. Crude group showed more strong reduction of PRL secretion, whereas the GN group showed moderate reduction (Fig. 5C). For the next experiment, PRLR mRNA levels were analyzed by real-time PCR. The mRNA expression level of PRLR was significantly elevated upon crude and GN treatment, which is consistent with the in vitro study (Fig. 5D).

\section{Discussion}

Homeostatic maintenance of PRL is essential since this hormone performs multiple physiological functions (14). General guidelines for hyperprolactinemia define the upper threshold of normal PRL at $25 \mu \mathrm{g} / 1$ for women and $20 \mu \mathrm{g} / 1$ 

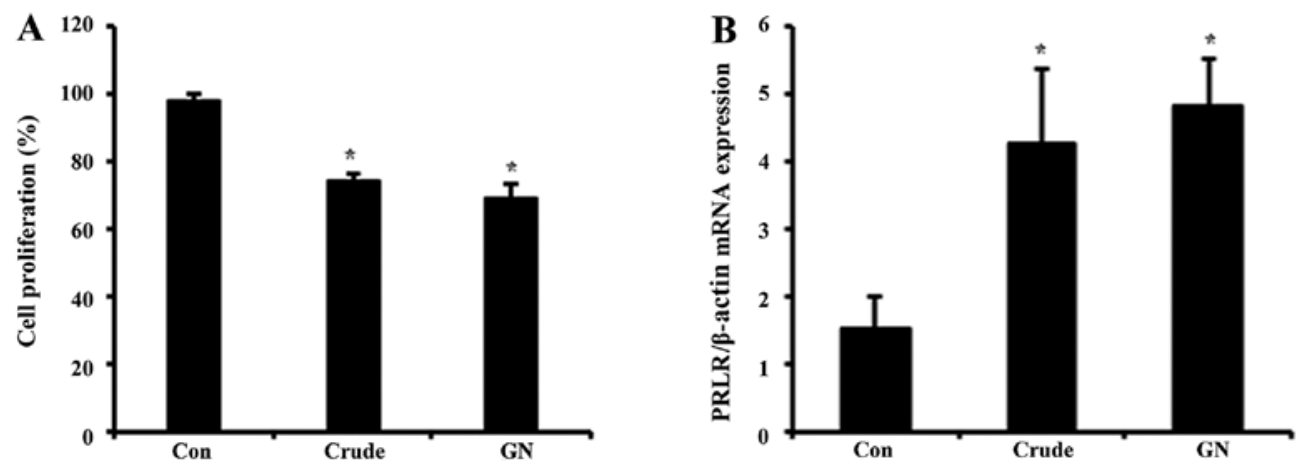

Figure 4. Effect of S. chinensis and GN on cell proliferation and cellular response. After treatment of GH3 cells with $\mathrm{Cr}$ and GN, cell proliferation was analyzed by MTT assay (A). Transcription level of PRLR (B) was analyzed by q-PCR after treatment of GH3 cells with Cr and GN. Data are expressed as the mean \pm SD. Transcription level of PRLR was normalized to that of $\beta$-actin. ${ }^{*} \mathrm{P}<0.05$ compared to the control group.
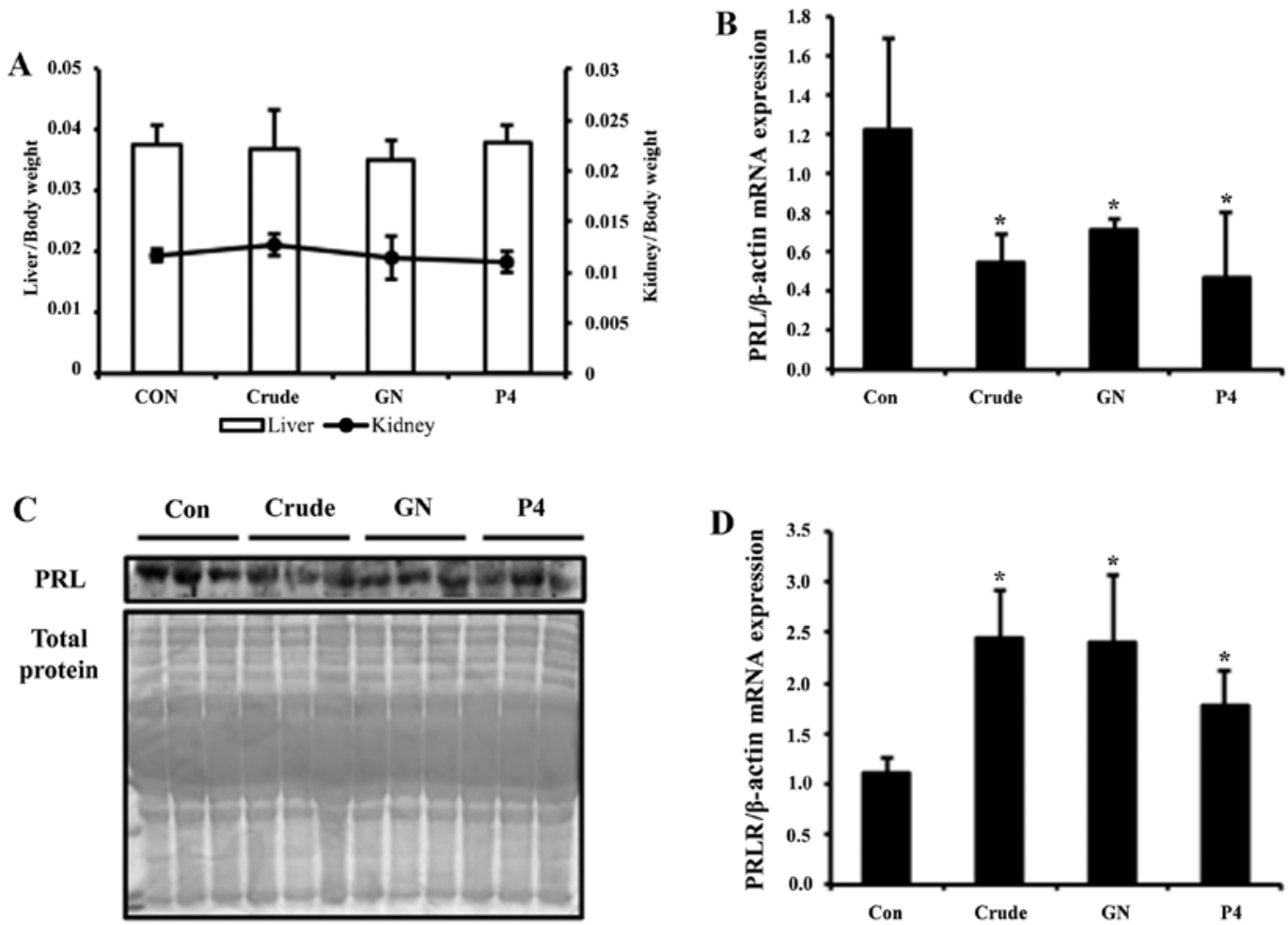

Figure 5. Regulation of PRL expression and secretion by S. chinensis and GN in immature rats. Regulation of PRL by S. chinensis and GN treated daily via oral injection for 7 days or $\mathrm{P} 4$ for 3 days in immature female SD rat (A) livers and kidney/body weight ratio. Pituitary mRNA (n=5) (B and D) and serum protein $(n=3)(C)$ levels of PRL were analyzed by q-PCR and western blot assay. Data are expressed as the means \pm SD. The mRNA and protein expression levels were normalized to that of total protein. ${ }^{*} \mathrm{P}<0.05$ compared to the control group.

for men, whereas hypoprolacinemia is defined as PRL levels below $3 \mu \mathrm{g} / 1$ in women and $5 \mu \mathrm{g} / 1$ in men (15-17). The representative cause of hyperprolactinemia is prolactinoma, and increased PRL levels can cause infertility and bone loss in both women and men. The goal of treatment for prolactinoma is to return PRL levels to normal, reduce tumor size, and correct any visual abnormalities (15). In some cases, surgical correction of prolacinoma has been shown to lower PRL levels to less than $250 \mathrm{ng} / \mathrm{ml}$ in $80 \%$ of patients. Even in patients with large tumors that cannot be completely removed, drug therapy may be able to reduce serum PRL levels back to the normal range (18). Dopamine is the chemical that normally inhibits PRL secretion, and dopamine agonists such as bromocriptine and cabergoline are effective medicines for treatment of hyperprolactinemia. However, bromocriptine and carbergoline are associated with side-effects such as nausea, vomiting, dizziness and hypotension $(18,19)$. To solve these problems, development of a treatment with fewer side-effects is required.

Natural products that generally show less side-effects than chemical drugs have become the main focus for the treatment of prolactinemia. Ginseng treatment was shown to reduce PRL secretion via a direct nitric oxide-mediated effect on the anterior pituitary (20). In another study, Ginkgo biloba extract improved sexual performance in young sexually experienced male rats via reduction of serum PRL levels (21). However, 
these studies focused on crude extracts of natural products and not on single compounds.

In the present study, we have for the first time investigated the therapeutic effects of extract and single compounds of S. chinensis on pituitary PRL regulation in vivo and in vitro. GH3 cells, which synthesize and secrete PRL, were treated with crude and single compounds, and GN remarkably reduced PRL mRNA and protein levels. PRL secretion was also reduced by GN in a dose- and time-dependent manner compared with the control. These results suggest that $S$. chinensis and its single compounds, especially GN, have potential as a natural medicine to treat hyperprolactinemia. In addition, we examined expression of the representative prolactin target gene, PRLR, in GH3 cells. As expected, PRL significantly reduced expression of its receptor. A previous study reported the rapid and prolonged downregulation of PRLR by PRL. In this study, PRL also caused degradation of PRLR, which is blocked by inhibitors of proteasomes and lysosomes (22). To further examine whether or not $S$. chinensis is effective for prolactinoma, we performed cell biability assay and observed that crude and GN successfully reduced pituitary carcinoma cell growth.

Following the in vitro study, we investigated the effect of S. chinensis crude and GN on PRL synthesis and secretion in immature female rats. In the present study, we employed sexually immature animals since sex steroid hormones are reported to regulate production of PRL. Specifically, P4 upregulates PRL synthesis in the endometrium but downregulates it in the myometrium and breast glandular tissue (23). Estrogen (E2) and P4 inhibit the stimulatory effects of PRL on milk production. More directly, it has been reported that E2 increases serum and pituitary PRL in ovariectomized rats, whereas P4 has inhibitory effects (24). In addition, precursor of E2 and P4, pregnenolone sulfate also increases prolactin production in the rat pituitary (25). In our experiments, we treated immature rats with crude, GN and P4. P4 was used as a positive control for the reduction of PRL based on previous studies (24). Similar to the in vitro study, crude and GN inhibited PRL but increased PRLR expression that is a target gene of PRL. Therefore, both in vivo and in vitro studies suggest that $S$. chinensis has a therapeutic effect on hyperprolactinoma.

In a previous study, $S$. chinensis was confirmed to possess various bioactivities and pharmacological applications. However, the mechanisms and bioactivities of its single compounds have not been well studied. GN is known to induce cellular apoptosis in hepatoma cells and leukemia cells $(26,27)$. Additionally, studies on the mechanism of GN-induced anticancer activity against two human tumor cell lines, ovary carcinoma cells and colon adenocarcinoma cells, have been shown (28). GN successfully inhibited growth of these cell lines through induction of different types of cell death. Although there are several studies available on the therapeutic potentials of GN and S. chinensis in other tissues, the effects of $S$. chinensis and its single compounds in the pituitary have not been addressed at all.

In summary, we examined the suppressive effects of S. chinensis on the synthesis and secretion of pituitary PRL both in vivo and in vitro. These findings demonstrate that S. chinensis can be applied to patients with PRL-related disorders such as hyperprolactinemia and prolactinoma.

\section{Acknowledgements}

The present study was supported by the National Research Foundation of Korea (NRF) grant funded by the Korea government (MOE) (no. 2014R1A1A2057387).

\section{References}

1. Hong GK, Payne SC and Jane JA Jr: Anatomy, physiology, and laboratory evaluation of the pituitary gland. Otolaryngol Clin North Am 49: 21-32, 2016.

2. Amar AP and Weiss MH: Pituitary anatomy and physiology. Neurosurg Clin N Am 14: 11-23, v, 2003.

3. Blackwell RE, Rodgers-Neame NT, Bradley EL Jr and Asch RH: Regulation of human prolactin secretion by gonadotropinreleasing hormone in vitro. Fertil Steril 46: 26-31, 1986.

4. Freeman ME, Kanyicska B, Lerant A and Nagy G: Prolactin: Structure, function, and regulation of secretion. Physiol Rev 80: 1523-1631, 2000.

5. Ben-Jonathan N and Hnasko R: Dopamine as a prolactin (PRL) inhibitor. Endocr Rev 22: 724-763, 2001.

6. Rillema JA: Mechanism of prolactin action. Fed Proc 39: 2593-2598, 1980.

7. McMurray RW: Estrogen, prolactin, and autoimmunity: Actions and interactions. Int Immunopharmacol 1: 995-1008, 2001.

8. Capozzi A, Scambia G, Pontecorvi A and Lello S: Hyperprolactinemia: Pathophysiology and therapeutic approach. Gynecol Endocrinol 31: 506-510, 2015.

9. Glezer A and Bronstein MD: Prolactinomas. Endocrinol Metab Clin North Am 44: 71-78, 2015.

10. Panossian A and Wikman G: Pharmacology of Schisandra chinensis Bail.: An overview of Russian research and uses in medicine. J Ethnopharmacol 118: 183-212, 2008.

11. Hancke JL, Burgos RA and Ahumada F: Schisandra chinensis (Turcz.) Baill. Fitoterapia 70: 451-471, 1999.

12. Chang HM and But P: Pharmacology and applications of Chinese Materia Edica. Volume 1. World Scientific, Singapore, pp199-209, 1986.

13. Bao T-T, Tu G-F, Liu G-T, Sun R-H and Song Z-Y: A comparison of the pharmacological actions of seven constituents isolated from fructus schizadrae (author's transl). Yao Xue Xue Bao 14: 1-7, 1979 (In Chinese).

14. Cowie AT: Physiological actions of prolactin. Proc R Soc Med 66: 861-862, 1973.

15. Mancini T, Casanueva FF and Giustina A: Hyperprolactinemia and prolactinomas. Endocrinol Metab Clin North Am 37: 67-99, viii, 2008.

16. Schwärzler P, Untergasser G, Hermann M, Dirnhofer S, Abendstein B and Berger P: Prolactin gene expression and prolactin protein in premenopausal and postmenopausal human ovaries. Fertil Steril 68: 696-701, 1997.

17. Ufearo CS and Orisakwe OE: Restoration of normal sperm characteristics in hypoprolactinemic infertile men treated with metoclopramide and exogenous human prolactin. Clin Pharmacol Ther 58: 354-359, 1995.

18. Bronstein MD: Potential for long-term remission of microprolactinoma after withdrawal of dopamine-agonist therapy. Nat Clin Pract Endocrinol Metab 2: 130-131, 2006.

19. Auriemma RS, Pivonello R, Ferreri L, Priscitelli P and Colao A: Cabergoline use for pituitary tumors and valvular disorders. Endocrinol Metab Clin North Am 44: 89-97, 2015.

20. Murphy LL and Lee TJ: Ginseng, sex behavior, and nitric oxide. Ann N Y Acad Sci 962: 372-377, 2002.

21. Yeh KY, Pu HF, Kaphle K, Lin SF, Wu LS, Lin JH and Tsai YF: Ginkgo biloba extract enhances male copulatory behavior and reduces serum prolactin levels in rats. Horm Behav 53: 225-231, 2008.

22. Lu JC, Piazza TM and Schuler LA: Proteasomes mediate prolactin-induced receptor down-regulation and fragment generation in breast cancer cells. J Biol Chem 280: 33909-33916, 2005. 
23. Zinger $M$, McFarland $M$ and Ben-Jonathan N: Prolactin expression and secretion by human breast glandular and adipose tissue explants. J Clin Endocrinol Metab 88: 689-696, 2003.

24. Chen CL and Meites J: Effects of estrogen and progesterone on serum and pituitary prolactin levels in ovariectomized rats. Endocrinology 86: 503-505, 1970.

25. Kang EJ, Hong SH, Lee JE, Kim SC, Yang HS, Yi PI, Lee SM and An BS: Pregnenolone sulfate regulates prolactin production in the rat pituitary. J Endocrinol 230: 339-346, 2016

26. Yim SY, Lee YJ, Lee YK, Jung SE, Kim JH, Kim HJ, Son BG, Park YH, Lee YG, Choi YW, et al: Gomisin N isolated from Schisandra chinensis significantly induces anti-proliferative and pro-apoptotic effects in hepatic carcinoma. Mol Med Rep 2: 725-732, 2009
27. Kim JH, Choi YW, Park C, Jin CY, Lee YJ, Park DJ, Kim SG, Kim GY, Choi IW, Hwang WD, et al: Apoptosis induction of human leukemia U937 cells by gomisin N, a dibenzocyclooctadiene lignan, isolated from Schizandra chinensis Baill. Food Chem Toxicol 48: 807-813, 2010.

28. Casarin E, Dall'Acqua S, Smejkal K, Slapetova T, Innocenti G and Carrara M: Molecular mechanisms of antiproliferative effects induced by Schisandra-derived dienzocyclooctadiene lignin ()-deoxychisandrin and (-)-gomisin $\mathrm{N}$ in human tumor cell lines. Fitoterapia 98: 241-247, 2014. 